American Journal of Applied Sciences 8 (4): 318-322, 2011

ISSN 1546-9239

(C) 2010 Science Publications

\title{
Utilization of Bone Adhesive to Produce Particleboards from Stems of Cotton Plant at the Pressing Temperature of $140^{\circ} \mathrm{C}$
}

\author{
${ }^{1}$ Komi Kadja, ${ }^{1}$ Magolmeena Banna, ${ }^{2}$ Kokou Esso Atcholi and ${ }^{1}$ Komla Sanda \\ ${ }^{1}$ Department of Mechanical Engineering and Design, Unit of Research on Agroresources and Environmental Health, \\ University of Lome, B.P. 1515 Lome, Togo \\ ${ }^{2}$ Department of Mechanical Engineering and Design, \\ University of Technology of Belfort-Montbeliard, 90010 BELFORT, Cedex, France
}

\begin{abstract}
Problem statement: To value agricultural residues, a study was carried out to investigate mechanical and physical properties of particleboards produced from stems of cotton (Gossypium hirsutum L.) by using bone adhesive. Approach: In order to obtain particleboards with minimum physical and mechanical properties as required in the conventional standards for general purpose particleboards, the optimum pressure temperature and the optimum pressure time and density used in this study, were respectively $140^{\circ} \mathrm{C}, 10-15 \mathrm{~min}$ and about $0.6-0,671 \mathrm{~g} \mathrm{~cm}^{-3}$. The optimum value of bone adhesive used in particleboards was $10 \%$. The Modulus Of Elasticity (MOE), Modulus Of Rupture (MOR), Traction strain $\left(\mathrm{R}_{\mathrm{r}}\right)$ and water absorption were determined at the pressure temperature of $140^{\circ} \mathrm{C}$. Results: The results revealed that the density of particleboards obtained from cotton plant at $140^{\circ} \mathrm{C}$ have neither notable influence on their mechanical properties, nor evolve in the same way as the constant mechanics of the particleboards. Conclusion: The bone adhesive could be used in particleboards production from the chips of cotton instead of the conventional binders which create the environmental problems.
\end{abstract}

Key words: Bone adhesive, modulus of elasticity, modulus of rupture, rate of adhesive, water absorption, Modulus Of Elasticity (MOE), Modulus Of Rupture (MOR)

\section{INTRODUCTION}

The demand for wood and other biomass-based particleboard materials have considerably increased due to the rate of population growth in the world; in fact, the world's population is increasing at the rate of approximately 90 million people per year (Alma et al., 2005, Osarenmwinda and Nwachukwu, 2010). Moreover, the world population currently consumes over 3.5 billion tons of green wood annually, which corresponds to about 0.7 tons per person. It has been thus demonstrated that if the consumption rate of wood fiber and the rate of population growth stay constant, demands for wood fiber will increase by over 60 million tons each year. Therefore, a huge imbalance between supply and demand will be inevitable. This is the predicted supply/demand scenario which we will face in the coming years (to 2010 and beyond) if nothing is done. Consequently, alternative fibers such as agrofibers and other plant fibers, recycling, more efficient conversion technologies and new products will play an important role in the wood fiber supply/demand map of the future (Osarenmwinda and Nwachukwu, 2010; Grigoriou et al., 2010).

A number of studies on the utilization of the wastes of agricultural crops in the production of the wood- and plastic-based particleboard materials have been conducted (Alma et al., 2005; Wang and Sun, 2002; Woodhams et al., 2004; Nourbakhsh, 2010); and the outcome of these studies showed that it will be beneficial to use the agro-fiber wastes in the production of particleboard material in terms of the environmental and socio-economic aspects. It has also been found that with the combination of wood chips, it is possible to produce pareticleboards from the wastes of agricultural crops: kenaf (Grigoriou et al., 2010); cotton (Osarenmwinda and Nwachukwu, 2010); bamboobased (Okubo et al., 2004) and date palm (Iskanderani, 2009), tea leaves (Kalaycioglu nd Nemli, 2006), date palms (Nemli et al., 2001) and peanut shells (Harriette et al., 2006) having physical and mechanical properties required in related standards.

Corresponding Author: Komi Kadja, Department of Mechanical Engineering and Design,

Unit of Research on Agroresources and Environmental health,

University of Lome, B.P. 1515 Lome, Togo 
In West Africa the total amount of cotton stalks is approximately 7400 tons $\mathrm{ha}^{-1}$. In Togo, the total amount of cotton (Gossypium hirsutum L.) stalks is approximately 250000 tons year ${ }^{-1}$; but this important agricultural waste is usually burned (Nenonene et al. 2009). Therefore, the aim of this study is to determine the possibility of using cotton stalks in particleboard production with bone adhesive.

The originality of this study is in the use of bone adhesive for the production of the particle boards. No literature refers to this adhesive in the production of the particle boards.

\section{MATERIALS AND METHODS}

To produce particleboards, cotton stalks (G. hirsutum) were collected from cotton farm in the localities of the town of Tsevie (Togo, West Africa); the stalks were then chipped by using hammermill. Bone adhesive obtained from the bones of cow was used to manufacture particleboards.

The experimental design for five-layer and adhesive bone-bonded particleboards from carpals is summarized in Table 1. The particleboards prepared were pressed at a maximum pressure of $11 \mathrm{bars}$ at $140^{\circ} \mathrm{C}$ for 20 and 25 min. Three experimental particleboards were produced for each design. Thus the particleboards obtained were conditioned at $20 \pm 1^{\circ} \mathrm{C}$ and $65 \pm 5 \%$ of relative humidity and the moisture content was about $12 \%$. The particleboards were then edge-trimmed to dimension $300 \times 300 \mathrm{~mm}$.

Some physical properties (density, water absorption) of the particleboards were determined according to TS EN 322 (1999), ASTM-D 1037 (1978) NFEN 326-1 (1994), NFEN 319 (1993) standards respectively.

We also determined several mechanical properties (Modulus Of Elasticity MOE; Modulus Of Rupture MOR; Traction strain $\mathrm{R}_{\mathrm{r}}$ ) of particleboards on a universal tester (Instron) by the following standards NF EN 310, 1993; NF B51-123 (1987). The average of 10 measurements was reported.

Table 1: Experimental design

\begin{tabular}{llllcl}
\hline Board type & $\begin{array}{l}\text { Pressure } \\
\text { time }(\mathrm{min})\end{array}$ & $\begin{array}{l}\text { Pressure } \\
(\mathrm{MPa})\end{array}$ & $\begin{array}{l}\text { Density } \\
\left(\mathrm{Kg} \mathrm{m}^{-3}\right)\end{array}$ & $\begin{array}{l}\text { Adhesive } \\
(\%)\end{array}$ & $\begin{array}{l}\text { Humidity } \\
(\%)\end{array}$ \\
\hline A & 25 & & 631.063 & 5.0 & \\
B & 25 & & 671.798 & 7.5 & \\
C & 20 & 1.1 & 661.764 & 10.0 & 20 \\
D & 20 & & 667.225 & 12.5 & \\
E & 20 & & 653.944 & 15.0 & \\
\hline
\end{tabular}

\section{RESULTS}

It is interesting to notice that there is no significant difference between all the particleboards made at the pressure times of 20 and 25 min in water absorption rate. All the particleboards had water absorption rate above $200 \%$. The A particleboards give the lowest water absorption rate to all the other particleboards under the same conditions.

The MOR values of the particleboards made from cotton stalks vary from 11.22-20.26 MPa. The modulus of rupture values of all the types of particleboards obtained in this study, were over the minimum modulus of rupture value required in ANSIA 208.11999 standard for general purpose particleboards which is $11 \mathrm{MPa}$ (Fig. 1). At the same conditions, the highest modulus of rupture value, $20.26 \mathrm{MPa}$ is obtained at $10 \%$ of bone adhesive having a density of $661.764 \mathrm{~kg} \mathrm{~m}^{-3}$, the lowest value of modulus of rupture, $11.22 \mathrm{MPa}$ is obtained at $5 \%$ bone adhesive for particleboards having a density of $631.063 \mathrm{~kg} \mathrm{~m}^{-3}$ and at an adequate pressure time of $25 \mathrm{~min}$.

The MOE values of the particleboards (Fig. 2) show that only two of the five types of particleboards obtained respected the ANSI A 208.11999 standards according to MOE and MOR values for a rate of bone adhesive of 10 and $12.5 \%$.

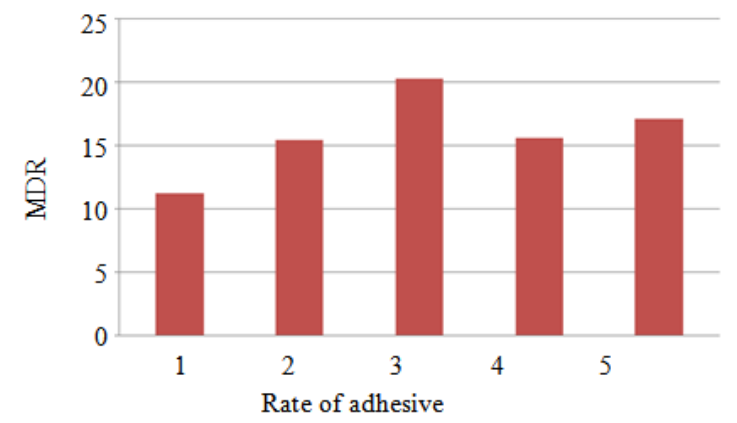

Fig. 1: MOR according to the rate of bone adhesive

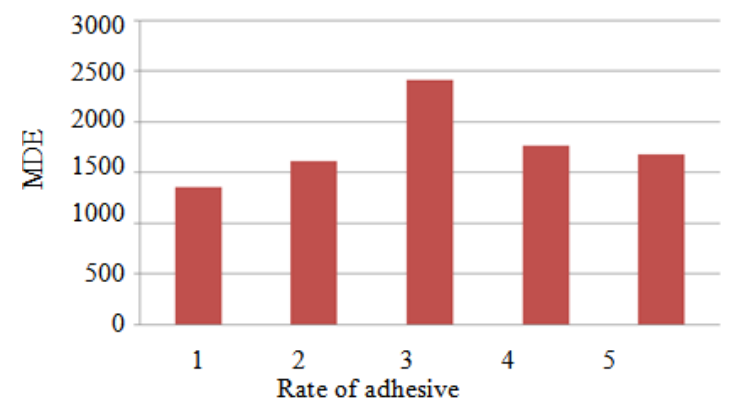

Fig. 2: MOE according to the rate of bone adhesive 319 
Am. J. Applied Sci., 8 (4): 318-322, 2011

Table 2: Results of physical and mechanical of particleboards from cotton stalk

\begin{tabular}{|c|c|c|c|c|c|c|c|c|}
\hline \multirow[b]{2}{*}{ Board type } & \multirow[b]{2}{*}{ Adhesive (\%) } & \multirow[b]{2}{*}{ Density $\left(\mathrm{Kg} \mathrm{m}^{-3}\right)$} & \multirow[b]{2}{*}{ Thickness (mm) } & \multicolumn{2}{|c|}{ Water absorption (\%) } & \multirow{2}{*}{$\begin{array}{l}\mathrm{MOE} \\
(\mathrm{MPa})\end{array}$} & \multirow{2}{*}{$\begin{array}{l}\text { MOR } \\
(\mathrm{MPa})\end{array}$} & \multirow{2}{*}{$\begin{array}{l}\mathrm{R}_{\mathrm{r}} \\
(\mathrm{MPa})\end{array}$} \\
\hline & & & & After $2 \mathrm{~h}$ & After $24 \mathrm{~h}$ & & & \\
\hline $\bar{A}$ & 5.0 & 631.063 & 4.65 & 155.56 & 211.11 & 1352.88 & 11.22 & 1.22 \\
\hline B & 7.5 & 671.798 & 4.43 & 222.22 & 288.89 & 1611.85 & 15.40 & 1.66 \\
\hline $\mathrm{C}$ & 10.0 & 661.764 & 4.45 & 200.00 & 237.50 & 2412.61 & 20.26 & 2.10 \\
\hline D & 12.5 & 667.225 & 4.32 & 212.50 & 262.50 & 1757.49 & 15.52 & 1.78 \\
\hline E & 15.0 & 653.944 & 4.36 & 175.00 & 212.50 & 1674.09 & 17.05 & 3.14 \\
\hline
\end{tabular}

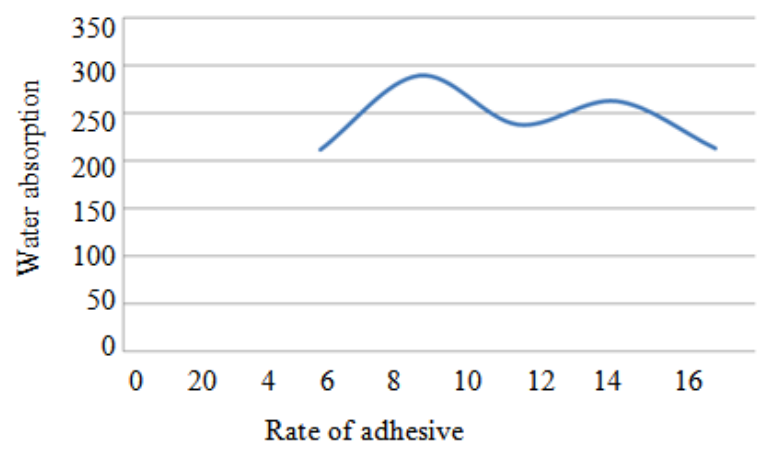

Fig. 3:Water absorption by the particleboards

Furthermore, the mechanical strength MOE MOR described in Table 2 for cotton stalks particleboards made with bone adhesive is determined to be somewhat higher than those of bamboo-based particleboards (Okubo et al., 2004), of kenaf (Kalaycioglu and Nemli, 2006); wood-waste chips (Yang et al., 2007).

The result obtained shows also that it possible to produce particleboards from cotton stalks with bone adhesive. Bone adhesive can take the place of urea formaldehyde in the production of particleboards without emission of formaldehyde.

Water absorption by the particleboards: In this study the particleboards obtained absorb more than $200 \%$ of water after two hours of immersion and more than $288 \%$ after $24 \mathrm{~h}$ (Fig. 3). These values are over the rate fixed by the standards which is $8 \%$. This behavior of water absorption requires that these particleboards should be used in dry medium and according to the standard EN 312, they are classified in the list of the particleboards $\mathrm{P}_{1}$ of' general use in dry medium.

The behavior of water absorption by these cotton plant particleboards fashioned with bone adhesive requires a later study which will allow carrying out cotton plant particleboards which could respect the water absorption standard.

The traction strain $\left(\mathbf{R}_{\mathbf{r}}\right)$ : The values of $\mathrm{R}_{\mathrm{r}}$ obtained in this study, are over the standards value which is $0.3 \mathrm{MPa}$. These results show that particleboards produced from cotton stalk have a good behavior at the traction.
Results according to the rate of bone adhesive used: Results of the test of inflection on the particleboards from cotton stalk revealed that, by varying the rate of the bone adhesive used, the obtained particleboards showed the following characteristics:

- The modulus of elasticity MOE varied between 1352.68 and $2412.61 \mathrm{MPa}$

- $\quad$ The breaking strength MOR varied between 11.22 and 20.2563 MPa

\section{DISCUSSION}

The values of MOR obtained are higher than the minimal values prescribed by the American standard ANSI A 208.1 1999. The values of MOE obtained, indicated an increase of the rate of the adhesive up to $10 \%$ and then a decrease, presenting the form of a parabola having a top at $10 \%$ (Table 2). It is obvious from Table 2, that the values of MOE and MOR obtained, indicate that only the adhesive rate of 10 and $12,5 \%$ allow to obtain particleboards respecting the criteria of particleboards of the M1 rank of standard ANSI A 208.1 1999. This same observation was made by Stöckel et al. (2010) and Ghalehno et al., (2010). The MOR values evolve in the same way as those of MOE and present a maximum at the same value of the rate of the adhesive. Cotton plants particleboards admit $10 \%$ like rate of adhesive allow obtaining the maximum values of MOE and MOR. The evolution of the mechanical properties according to the rate of adhesive is limited to $10 \%$, beyond this value, these properties decreased. When the rate of the adhesive used is lower than $10 \%$ the particleboards obtained respect rather the criteria of the rank LD1 where constant mechanics is weaker than of standard ANSI A 208.11999 of the M1. In all the cases these panels are utilizable for the heat isolation or the wall lining or more generally in the fields where they do not undergo enough request. This observation was also done by Harriette et al. (2006); Ashor and Nourbakhs, (2008); and Iskanderani (2009). The density of cotton plant particleboards obtained at $140^{\circ} \mathrm{C}$ have neither notable influence on their mechanical properties, nor evolve in the same way as 
the constant mechanics of the particleboards. A manufacturer can initiate the production of cotton plant particleboards with bone adhesive without fear and obtain particleboards respecting the international standards at the rate of $10 \%$. Thus, these experimental results showed that the parameters were found to be effective on the physical (thickness swelling) and mechanical (modulus of rupture and internal bond strength) properties.

\section{CONCLUSION}

The results indicated that it is possible to produce particleboards from cotton stalk with bone adhesive and to obtain the standards ANSI A 208.11999 considering MOE and MOR values. The rate of water absorption by the particleboards produced from cotton stalk by using bone adhesive does not answer the criteria fixed by the standards. Therefore, the particleboards obtained from cotton stalks with bone adhesive must be used in dry condition. In general, mechanical properties (MOE, MOR, $R_{r}$ ) of particleboards produce from cotton stalk respect the minimum criteria fixed by standards ANSI A 208.11999 except that of water absorption. The bone adhesive becomes then a potential binding to be used in particleboards production from cotton stalk instead of the conventional binders which create the environmental problems.

\section{ACKNOWLEDGEMENT}

We are grateful to the laboratory of 'Unite de Recherche sur les Agroressources et Sante Environnementale (URASE)' for sponsoring this project.

\section{REFERENCES}

Alma, M.H., H. Kalaycoglu, I. Bektas and A. Tutus, 2005. Properties of cotton carpel-based particleboards. Ind. Crops Prod., 22: 141-149. DOI: 10.1016/J.INDCROP.2004.08.001

Ashor, A. and A. Nourbakhs, 2008. Effect of press cycle time and resin content on physical and mechanical properties of particleboard panels made from the underutilized low-quality raw materials. Ind. Crops Prod., 28: 225-230. DOI: 10.1016/j.indcrop.2008.02.015

Ghalehno, M.D., M. Nazerian and A. Bayatkashkooli, 2010. Influence of utilization of bagasse in surface layer on bending strength of three-layer particleboard. European J. Wood Wood Prod., DOI: $10.1007 /$ s00107-010-0441
Grigoriou, A., C. Passalis and E. Voulgradis, 2010. Experimental particleboards from KENAF plantations grown in Greece: Versuchsspanplatten aus griechischen Kenaf Plantagen. European J. Wood Produ., 58: 309-314. DOI: 10.1007/s001070050435

Harriette, L.B., M. Jorg and J.A.O. Martie, 2006. Mechanical properties of short-flax-fibre reinforced compounds. Compos: A., 37, pp: 15911604.

DOI: 10.1016/J.COMPOSITESA.2005.10.011

Iskanderani, F.I., 2009. Influence of process variables on the bending strength of particleboard produced from Arabian date palm mid-rib chips. Int. J. Polymeric Mat., 58: 49-60. DOI: 10.1080/00914030802461964

Kalaycıoglu, H. and G. Nemli, 2006. Producing composite particleboard from kenaf (Hibiscus cannabinus L.) stalks. Ind. Crops Prod., 24: 177180. DOI: 10.1016/j.indcrop.2006.03.011

Nemli, G., H. Kalaycioglu and H. Alp, 2001. Suitability of date palm (Phoenix dactyliferia) branches for particleboard production. European J. Wood Wood Prod., 59: 411-412. DOI: 10.1007/s00107-0010257

Nenonene, A.Y., K. Koba, K. Sanda and L. Rigal, 2009. Composition and binding properties of mucilages from stem bark of grewia venusta and calyx of bombax costatum, two tropical plants growing wild in Togo. Bangladesh J. Sci. Ind. Res. 44: 247-253. DOI: 10.3329/bjsir.v44i2.3681

Nourbakhsh, A., 2010. Mechanical and thickness swelling of particleboard composites made from three-year-old poplar clones. J. Reinforced Plastics Comp., 29: 481-489. DOI: 10.1177/0731684408097771

Okubo, K., T. Fujii and Y. Yamamoto, 2004. Development of bamboo-based polymer composites and their mechanical properties. Composites PartA: Applied Sci. Manufactur., 35: 377-383.

DOI: 0.1016/J.COMPOSITESA.2003.09.017

Osarenmwinda, J.O. and J.C. Nwachukwu, 2010. Development of composite material from agricultural wastes. Int. J. Eng. Res. Africa, 3: 42-48.

DOI: 10.4028/www.scientific.net/JERA.3.42

Stöcke, F., J. Konnerth, W. Kantner, J. Moser and W. Gindl, 2010. Mechanical characterisation of adhesives in particle boards by means of nanoindentation: Mechanische Charakterisierung von Klebstoffen in Spanplatten mittels Nanoindentation. European J. Wood Wood Prod., 68: 421-426. DOI: 10.1007/s00107-009-0380-7 
Wang, D. and X.S. Sun, 2002. Low density particleboard from wheat straw and corn pith. Ind. Crops Prod., 15: 47-50. DOI: 10.1016/S09266690(01)00094-2

Woodhams, R.T., G. Thomas and D.K. Rodgers, 2004. Wood fibers as reinforcing fillers for polyolefins. Polym. Eng. Sci., 24: 1166-1171. DOI: 10.1002/pen.760241504
Yang, T.H., C.J. Lin, S.Y. Wang and M.J. Tsai, 2007. Characteristics of particleboard made from recycled wood-waste chips impregnated with phenol formaldehyde resin. Build. Environ., 42: 189-195. DOI: 10.1016/J.BUILDENV.2005.08.028 